\title{
Analysis of spatial variation of credit risk of China listed companies based on spatially varying coefficient logistic models
}

\author{
Ying $\mathrm{Du}^{1, *}$, and Chanchan $\mathrm{Wang}^{2}$ \\ ${ }^{1}$ School of Economics and Finance, Xi'an International Studies University, Xi'an, Shaanxi, China \\ ${ }^{2}$ School of Mathematics and Statistics, Xi'an Jiaotong University, Xi'an, Shaanxi, China
}

\begin{abstract}
Nowadays, since the booming economy of china, the development of financing behaviors, represented by the financial took it such as stocks and bonds, is increasing continuously in our country, meanwhile, it is more and more prominent that the credit risks problems brought by the frequent defaults in credit transactions. Analysis of credit risk characteristics become a very important study topic. Whether A-share listed companies in some provinces in the central and eastern regions of my country being special treatment (ST) are used as a sample to study credit risk. Based on the spatially varying coefficient logistic models, this paper analyzes the spatial variation characteristics of industry type and ownership nature affecting the probability of listed companies being ST. The results show that there is a large spatial variation in the intensity of the influence of these factors on the risk of listed companies being ST.
\end{abstract}

\section{Introduction}

With the rapid development of Internet finance, the pace of financial innovation is accelerating, and financial risks are accumulation in the process. The various financial risks represented by market risk, liquidity risk, business risk, etc. will eventually be manifested by credit risk, specifically the default behavior in credit transactions, therefore, it is of great significance to analyze the factors affecting credit risk. Among them, industry is the basis of the overall operation of the economy, and differences in industry characteristics (such as competitive environment, ease of entry, average return on investment period, etc.) will directly affect the credit risk status of inter-industry enterprises, resulting in different relative stability and health of the business environment ${ }^{[1]}$. The nature of ownership is an important attribute of a company. Under different ownership structures, due to differences in property rights, business environment, and organization and management, companies exhibit different organizational forms, incentive mechanisms, and production capacity, and therefore, differences in ownership also have a certain impact on the credit status of companies. As far as we know, the impact of ownership on credit risk has been neglected in the current studies.

\footnotetext{
* Corresponding author: duyingxjtu@aliyun.com
} 
In addition, factors such as unbalanced resource distribution, local policy differences, and different technological inputs have led to different characteristics in the development of industries in different regions, causing different attributes of industry companies to vary with geographical locations, and these differences have different effects on corporate risks. Studying the influence of different industries and ownership properties on the company's credit risk level and the spatial variation pattern of the impact can enable investors to have an intuitive understanding of how various factors affect the credit risk of an enterprise, which is conducive to identifying groups of enterprises with different risk levels and make beneficial investment strategies. For the spatial research of credit risk, most of them currently focus on qualitative analysis[2,3], and there are few empirical analysis on spatial measurement models of credit risk. Therefore, there is still much room for research on the spatial change characteristics of different corporate attributes affecting credit risk.

On April 22, 1998, the Shanghai and Shenzhen Stock Exchanges announced a special treatment ("ST", for short) for the stock trading of listed companies with abnormal financial status and other abnormal financial conditions, as a risk warning to investors. There are two main types of abnormalities: firstly, the net profit of a listed company is negative for two fiscal; Secondly, the audited net assets value per share of a listed company in the last fiscal year is lower than the face value of the share. The occurrence of being ST, which has a negative impact on the stock price of a listed company, will lead to certain asset losses for investors, and therefore can be regarded as a default risk. Due to the availability of data and the important role of listed companies in China's economic development, this paper takes the ST probability of A-share listed companies in Shanghai and Shenzhen stock markets in eastern China as a sample to study credit risk. Based on the spatial varying coefficient Logistic model, we analyze the spatial variation characteristics of that how the type of industry, the nature of ownership and other factors affecting the probability of listed companies being ST.

\section{Model selection and data collection}

\subsection{Spatially varying-coefficient logistic models}

In order to explore the spatial non-stationarity of the data regression relationship, Brunsdon and Fotheringham ${ }^{[4]}$ established a spatial variable coefficient regression model and proposed geographic weighted regression method. Then, it has been widely used in spatial data analysis in many fields such as geography, environmental science, ecology, and economics $^{[5-6]}$. Xu et al. ${ }^{[7]}$ further extended the related ideas and conclusions to the generalized linear models, and established a generalized spatial varying coefficient regression model. Because of the good performance of the Logistic model in the generalized linear model in the field of credit risk ${ }^{[8]}$, and the fact that the logistic model of the spatially varying coefficients can reflect the spatial change characteristics of the influence of independent variables on the probability of occurrence of the event by introducing the geographic location of the data into the regression coefficients, we choose the spatially varying coefficient Logistic model to conduct credit risk analysis research. The corresponding spatially varying coefficient Logistic model is

$$
\ln \left[\frac{\mu\left(X_{i}, s_{i}\right)}{1-\mu\left(X_{i}, s_{i}\right)}\right]=\tilde{X}_{i}^{T} \beta\left(u_{i}, v_{i}\right), i=1,2, \cdots, n \quad \text { or } \quad \mu\left(X_{i}, s_{i}\right)=\frac{\exp \left(\tilde{X}_{i}^{T} \beta\left(u_{i}, v_{i}\right)\right)}{1+\exp \left(\tilde{X}_{i}^{T} \beta\left(u_{i}, v_{i}\right)\right)}, i=1,2, \cdots, n .
$$


Here, $X_{i}=\left(X_{i 1}, X_{i 2}, \cdots, X_{i, p-1}\right)$ is the observation value of the independent variable $X_{1}, X_{2}, \cdots, X_{p-1}$ at the geographic location $s_{i}=\left(u_{i}, v_{i}\right), i=1,2, \cdots, n . \quad \widetilde{X}_{i}=\left(1, X_{i}^{T}\right)^{T}=$ $\left(X_{i 0}, X_{i 1}, \cdots, X_{i, p-1}\right)^{T}, i=1,2, \cdots, n$, where $X_{i 0}=1$. If there are $m_{i}$ independent observations at each location $\left(X_{i}, s_{i}\right), i=1,2, \cdots, n, Y_{i}$ denotes the number of occurrences of an event $A$ in the $m_{i}$ observations at $\left(X_{i}, s_{i}\right) . \mu\left(X_{i}, s_{i}\right)$ denotes the probability of an event $A$ occurring during the observation at $\left(X_{i}, s_{i}\right)$, then $Y_{i} \sim B\left(m_{i}, \mu\left(X_{i}, s_{i}\right)\right), i=$ $1,2, \cdots, \mathrm{n}$.

\subsection{Variable selection and data collection}

Regarding the industry attributes of listed companies, the Shenyin \& Wanguo industry classification standard system is used to subdivide the industry categories into 28 primary industries. Due to the different status of the industry in the industry chain, it may lead to different development characteristics. Therefore, the industry is further divided into five major categories, and the detailed classification is shown in Table 1 below. The variations selected is presented in Table 2.

Table 1. Industry classification of listed companies.

\begin{tabular}{|c|c|}
\hline General Classification & Shenyin \& Wanguo First-tier Industries \\
\hline Category One & $\begin{array}{l}\text { Agriculture, forestry, animal husbandry, and } \\
\text { fishery }\end{array}$ \\
\hline Category Two ( upstream industries) & $\begin{array}{l}\text { Mining, chemicals, iron and steel, and } \\
\text { non-ferrous metals }\end{array}$ \\
\hline Category Three (midstream industries) & $\begin{array}{l}\text { Building materials, building decoration, electrical } \\
\text { equipment, mechanical equipment, and national } \\
\text { defense industry }\end{array}$ \\
\hline Category Four (downstream industries) & $\begin{array}{l}\text { Automobiles, real estate, electronics, computers, } \\
\text { household appliances, textile and clothing, light } \\
\text { manufacturing, food and beverage, and medical } \\
\text { biology }\end{array}$ \\
\hline Category Five & $\begin{array}{l}\text { Transportation, public utility, non-bank finance, } \\
\text { banking, communication, media, commercial } \\
\text { trade, leisure services, and comprehensive } \\
\text { industry }\end{array}$ \\
\hline
\end{tabular}

Table 2. Specific significance of different indexes.

\begin{tabular}{|c|c|}
\hline Indexes & Significance \\
\hline $\mathrm{X}_{1}$ & $\begin{array}{l}\mathrm{X}_{1}=1 \text {, indicating that the industry is in the Category One; } \mathrm{X}_{1}=0 \text {, indicating that the } \\
\text { industry attribute is "others" }\end{array}$ \\
\hline $\mathrm{X}_{2}$ & $\begin{array}{l}\mathrm{X}_{2}=1 \text {, indicating that the industry is in the Category Two; } \mathrm{X}_{2}=0 \text {, indicating that the } \\
\text { industry attribute is "others" }\end{array}$ \\
\hline $\mathrm{X}_{3}$ & $\begin{array}{l}\mathrm{X}_{3}=1 \text {, indicating that the industry is in the Category Three; } \mathrm{X}_{3}=0 \text {, indicating that the } \\
\text { industry attribute is "others" }\end{array}$ \\
\hline $\mathrm{X}_{4}$ & $\begin{array}{l}\mathrm{X}_{4}=1 \text {, indicating that the industry is in the Category Four; } \mathrm{X}_{4}=0 \text {, indicating that the } \\
\text { industry attribute is "others" }\end{array}$ \\
\hline & $\mathrm{X}_{1}=\mathrm{X}_{2}=\mathrm{X}_{3}=\mathrm{X}_{4}=0$, indicating that the industry is in the Category Five \\
\hline $\mathrm{X}_{5}$ & $\mathrm{X}_{5}=1$, indicating that the nature is "local state-owned enterprise"; $\mathrm{X}_{5}=0$, "others" \\
\hline $\mathrm{X}_{6}$ & $\mathrm{X}_{6}=1$, indicating that the nature is "private enterprise": $\mathrm{X}_{6}=0$, "others" \\
\hline $\mathrm{X}_{7}$ & $\mathrm{X}_{7}=1$, indicating that the nature is "central state-owned enterprise"; $\mathrm{X}_{7}=0$, "others" \\
\hline $\mathrm{X}_{8}$ & $\mathrm{X}_{8}=1$, indicating that the nature is "foreign-invested enterprise"; $\mathrm{X}_{8}=0$, "others" \\
\hline $\mathrm{Y}$ & $\begin{array}{l}\mathrm{Y}=1 \text {, indicating that the sample received ST at least once or are under ST; } \mathrm{Y}=0 \text {, } \\
\text { indicating that the sample has never suffered ST. }\end{array}$ \\
\hline
\end{tabular}


In view of the small number of listed companies in the western region of China, this paper mainly considers the companies located in Central and Eastern of China and listed before December 31, 2014. The selected regions include Shanxi, Hebei, Beijing, Tianjin, Liaoning, Shandong, Henan, Jiangsu, Anhui, Hubei, Hunan, Guangdong, Jiangxi, Zhejiang and Fujian, 16 provinces or municipalities in total. There are 2,083 companies listed before December 31, 2014in the selected region, among which 343 companies had received ST at least once or are under ST by 2017. The data all comes from Wind.

\section{Analysis of spatial variation characteristics of credit risk}

The differences of policy support and technology investment of listed companies in different regions usually have different impacts on their operation. Based on the sample data of 2083 listed companies, we establish the spatial varying coefficient logisitc model, estimate the parameters by using the local linear maximum likelihood estimation method, and analyze the variation characteristics of the influence of each factor on the probability of listed companies being ST.
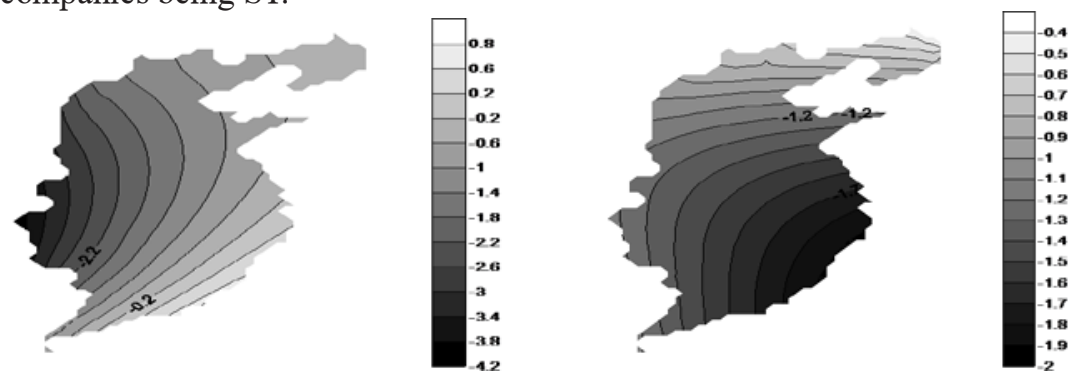

Fig. 1. Contours of the estimated values of (a) $\beta_{0}\left(u_{i}, v_{i}\right)+\beta_{1}\left(u_{i}, v_{i}\right) ;(b) \beta_{0}\left(u_{i}, v_{i}\right)+\beta_{2}\left(u_{i}, v_{i}\right)$.

Firstly, we use the contour line method to show how the probability of being ST varies among geographically located companies in the same industry when the ownership properties of the listed companies are the same. Controlling of the other attributes, the contours of the estimated values $\beta_{0}\left(u_{i}, v_{i}\right)+\beta_{1}\left(u_{i}, v_{i}\right), \beta_{0}\left(u_{i}, v_{i}\right)+\beta_{2}\left(u_{i}, v_{i}\right), \beta_{0}\left(u_{i}, v_{i}\right)+$ $\beta_{3}\left(u_{i}, v_{i}\right), \beta_{0}\left(u_{i}, v_{i}\right)+\beta_{4}\left(u_{i}, v_{i}\right)$.The results are shown in Figure 1-2.

From Figure 1 (a), we can see that, with the same ownership, the probability of Listed Companies in agriculture, forestry, animal husbandry, fishery and other industries, which are located in the provinces of Hubei, Hunan, Shanxi, Henan and other central regions of China, being ST is relatively smaller, while those in Guangdong, Liaoning, Fujian and other coastal and northern provinces, This is consistent with the distribution of the Category One industry in China. The central region is the key area of China's agriculture, forestry, animal husbandry and fishery industry. The mature sales channels and industrial chain operation play a certain role in protecting the listed companies in these industries.
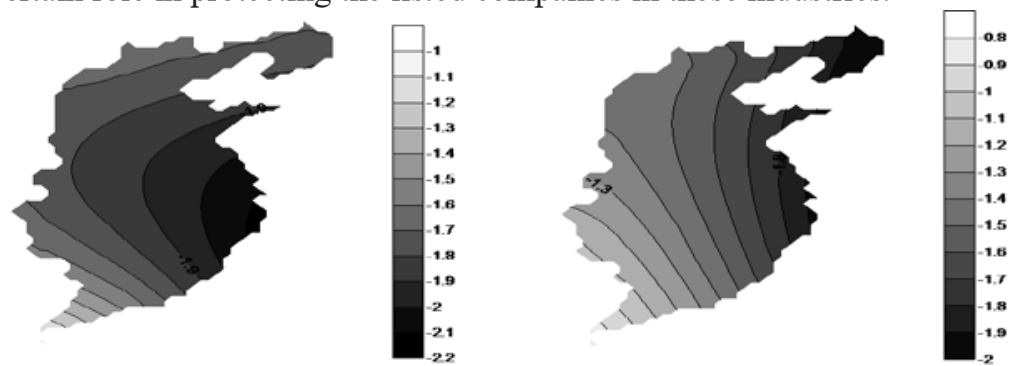

Fig. 2. Contours of the estimated values of $(a) \beta_{0}\left(u_{i}, v_{i}\right)+\beta_{3}\left(u_{i}, v_{i}\right) ;(b) \beta_{0}\left(u_{i}, v_{i}\right)+\beta_{4}\left(u_{i}, v_{i}\right)$. 
From Figure 1(b), it can be seen that the probability of being ST of listed companies in the Category Two industry is gradually showing an increasing trend from the southern provinces of Guangdong and Hunan to the northern provinces of Hebei, Liaoning, municipalities of Beijing, Tianjin and other provinces and cities. The main reason is that for the steel, chemical industry, mining and non-ferrous metal industry, the distribution of enterprises is obviously more in the north than in the south. Due to the serious overcapacity in the north and the obvious shortage of supply in the south, the operating efficiency of enterprises in the industry in the northeast is significantly different. Thus, the industry bears a higher credit risks in the northern region compared with that in the southern region.

It can be seen from Figure 2 (a) that the probability of the listed companies being ST in the midstream industries such as construction materials, building decoration, electrical equipment, mechanical equipment, national defense and military industry, is relatively small compared with that in Hebei, Liaoning, Beijing, Shanxi and other northern provinces. While for the companies around Maoming and Zhanjiang in Guangdong Province, the probability of being ST in the midstream industries is increasing gradually.

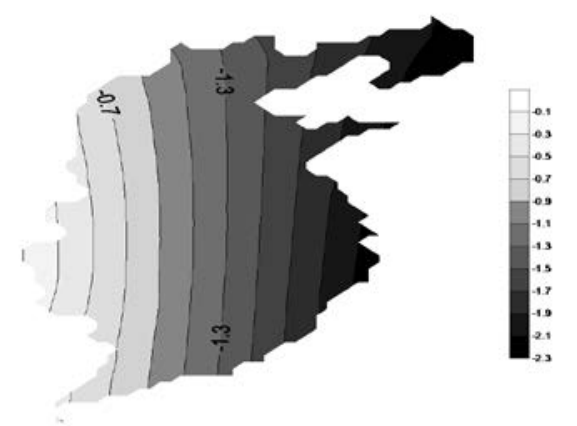

Fig. 3. Contours of the estimated values of $\beta_{0}\left(u_{i}, v_{i}\right)$.

From Figure 2 (b), it can be seen that in Shanghai, Hangzhou, Dalian and other coastal cities, the probability of being ST of Listed Companies in industries such as automobile, real estate, electronics, computer, household appliances etc., is smaller than that in inland areas, which is similar to the change trend of ST probability of listed companies in industries like transportation, public utilities, banks and so on as shown in Figure 3. The credit risk of the two industries both shows an increasing trend from east to west. This may be due to the fact that the fourth industry which is at the end of the industrial chain, like the fifth comprehensive industry, is closely related to people's life and enterprise operation. Therefore, in the economically developed areas such as the eastern coast, the demand is higher and the probability of companies being ST is smaller than that in the western inland areas.
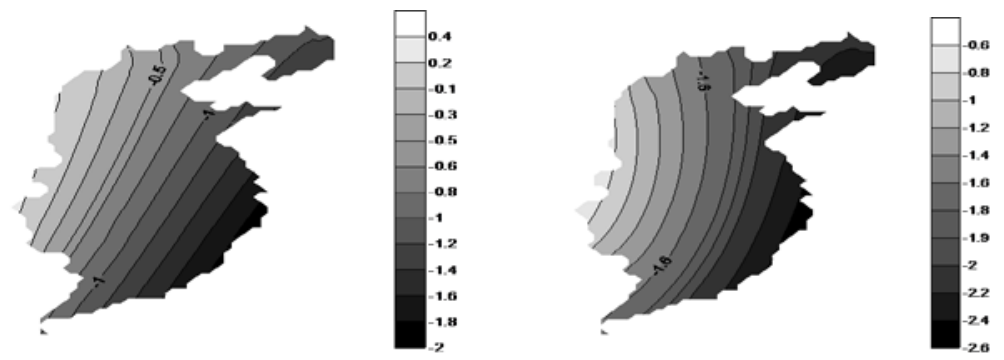

Fig. 4. Contours of the estimated values of $(a) \beta_{0}\left(u_{i}, v_{i}\right)+\beta_{5}\left(u_{i}, v_{i}\right)$; (b) $\beta_{0}\left(u_{i}, v_{i}\right)+\beta_{6}\left(u_{i}, v_{i}\right)$. 

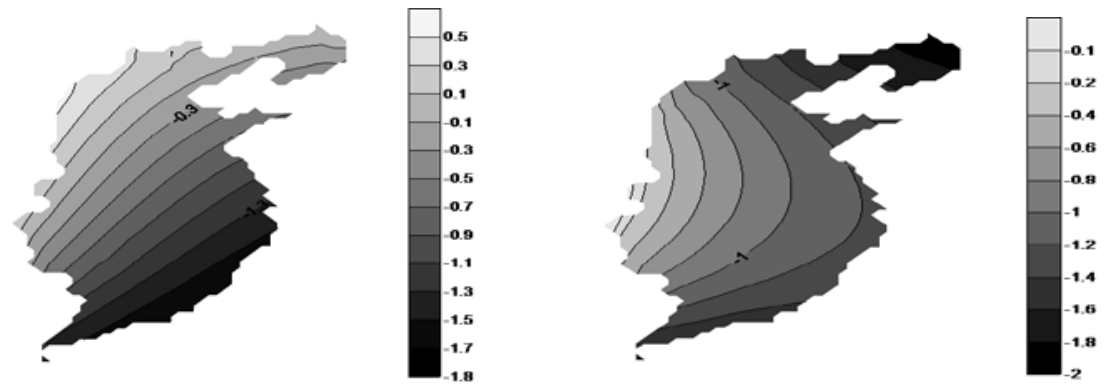

Fig. 5. Contours of the estimated values of (a) $\beta_{0}\left(u_{i}, v_{i}\right)+\beta_{7}\left(u_{i}, v_{i}\right) ;(b) \beta_{0}\left(u_{i}, v_{i}\right)+\beta_{8}\left(u_{i}, v_{i}\right)$.

Secondly, in order to observe the spatial trend of the probability of being ST for a listed company with different ownership attributes under the condition that the industry attribute factors remain unchanged, we use the isoline map of the estimated value of $\beta_{0}\left(u_{i}, v_{i}\right)+$ $\beta_{5}\left(u_{i}, v_{i}\right), \quad \beta_{0}\left(u_{i}, v_{i}\right)+\beta_{6}\left(u_{i}, v_{i}\right), \beta_{0}\left(u_{i}, v_{i}\right)+\beta_{7}\left(u_{i}, v_{i}\right), \beta_{0}\left(u_{i}, v_{i}\right)+\beta_{8}\left(u_{i}, v_{i}\right), \beta_{0}\left(u_{i}, v_{i}\right)$. The results are shown in Figure 3-5.

From figures 3, 4 and 5 (a), we can see that the ST probability of listed companies with ownership of local state-owned enterprises, private enterprises, central state-owned enterprises and other types of enterprises shows an increasing trend from the southeast coastal areas to the western inland areas, while Figure 5 (b) shows that the trend of ST probability of listed companies with foreign capital gradually increases from the south to the north. This may be related to the fact that southeast China is close to Hong Kong, Macao and other places where international capital is gathered. Therefore, foreign-invested enterprises in Southeast China, especially in Guangdong Province, have relatively low credit risk.

\section{Summary}

In China's securities market, the change of corporate credit status is the result of the comprehensive influence of many factors that can be grouped into three categories: macro factors include the influence of national policies and financial crisis; meso factors include industry characteristics, organizational forms and regional unique geographical culture; micro factors include the development of their own operation and financial conditions. The paper focuses on the impact of meso factors. Considering the influence of macro factors, micro factors and other meso factors, in order to establish a more efficient credit risk assessment model, we need to further study the variable selection, statistical inference and other related issues of the spatial varying coefficient logistic model.

\section{References}

1. J.H. Li, G. Han, X.P. Han. Research on credit risk measurement model based on credit portfolio view. Indust Techn Econ, 27, 46-48(2008).

2. J. Tao, K.Z. Liu, Z. Zhang. The impact of physical and geographical environment on the development performance of private enterprises: a comparative analysis based on the eastern and western regions. Market Moder, 26, 297-298(2005).

3. Z.X. Sang. Distribution characteristics of ST Listed Companies Based on trend surface analysis. J East China Univ Sci Techn, 26, 31-37(2011).

4. C. Brunsdon, A.S. Fortheringham, M.E. Charlton. Geographically weighted regression: A method for exploring spatial nonstationarity. Geogr Anal, 28, 281-298(1996). 
5. Y. Zhang, C.L. Mei. Spatial characteristics of commercial housing prices in central and eastern China based on geographically weighted regression. J Appl Stat Manag, 31, 898-905(2012).

6. X. Chen et al. Spatial dynamic differences and influencing factors of China's financial development level. Finan Forum, 23, 45-56(2018).

7. M. Xu, C.L. Mei, S.J. Hou. Local-Linear likelihood estimation of geographically weighted generalized linear models. J Spat Sci, 61, 99-117(2016).

8. M. Kukuk, M. Ronnberg. Corporate credit default models: a mixed logit approach. Rev Quant Finan Acc, 40,467-483(2013). 